\title{
Prevalence Of Gingival Recession In Patients Undergoing Orthodontic Treatment in the Age Group Of 18 To 25 Years - A Retrospective Study
}

Research Article

\author{
Janhvi Manohar ${ }^{1}$, Jaiganesh Ramamurthy ${ }^{2 *}$, S.P. Saravana Dinesh ${ }^{3}$
}

${ }^{1}$ Saveetha Dental College and Hospitals, Saveetha Institute of Medical and Technical Sciences, Saveetha University, Chennai, India.

${ }^{2}$ Professor and Head, Department of Pedodontics, Saveetha Dental College and Hospitals, Saveetha Institute of Medical and Technical Sciences, Saveetha University, Chennai, India.

${ }^{3}$ Professor and Head of Department, Department of Orthodontics, Dental College and Hospitals, Saveetha Dental College and Hospitals, Saveetha Institute of Medical and Technical Sciences, Saveetha University, Chennai, India.

\section{Abstract}

\begin{abstract}
Periodontitis is a chronic inflammatory disease which is characterised by means of periodontal tissue damage due to an interaction between bacteria and the host immune system. The most important event in chronic periodontitis is the destruction of periodontal tissue which manifests as clinical loss of attachment of gingiva. Gingival recession is characterised by the apical migration of gingival margin from the cementoenamel junction. It can be localised or generalised and associated with at least one tooth surface. It leads to aesthetic problems and apart from periodontitis, it is often caused due to forces by orthodontic tooth movements or forces due to eccentric bite such as crossbite which occurs as a result of application of pressure and tension on alternate surfaces on the periodontal ligament and thus the bone thus causing bone remodelling. This study aims to assess the prevalence of gingival recession in patients undergoing orthodontic treatment in the age 18 to 25 years. A retrospective study was performed among patients visiting the department of Orthodontics in a private dental hospital who were undergoing orthodontic treatment and they were assessed by intraoral photographs taken to check for gingival recession. Results were collected, tabulated and Pearson Chi-square test done using SPSS by IBM to assess if there is a correlation in cases of orthodontic treatment between plaque accumulation and gingival recession and checked for gender prevalence. Out of 86,000 case records, 347 patients were chosen for the study who fulfilled the inclusion criteria, $50.3 \%$ were observed to have gingival recession ( $p>0.05$, non significant), wherein majority were male patients and the gingival recession observed had no correlation with or was independent of plaque accumulation which was inferred by assessing their plaque index scores. $40.06 \%$ of the sample were observed with Miller's class I gingival recession, $0.6 \%$ reported with Miller's class II gingival recession.
\end{abstract}

Keywords: Gingival Recession; Orthodontic Treatment; Gingiva; Periodontitis.

\section{Introduction}

Periodontitis is a chronic inflammatory disease characterised by periodontal tissue damage due to an interaction between bacteria and the host immune system [1]. The most important event in chronic periodontitis is the destruction of periodontal tissue which manifests as clinical loss of attachment of gingiva. Gingival recession is characterised by apical migration of gingival margin from the cementoenamel junction and it is one of the most common aesthetic concerns related to the periodontal tissue [2] and can affect upto $90 \%$ of the population [3]. It can be localised or generalised depending on the etiological agent [4]. Gingival recession usually leads to an aesthetic problem and mobility of teeth due to progressive destruction; may also be associated with dentin hypersensitivity and/or root caries and cervical abrasion [5].

Several mechanical, chemical and biological factors play a role in the development of gingival recession but not necessarily simultaneous to the etiological process or equally. Mechanical factors such as traumatic tooth brushing and bruxism are suggested to initiate or worsen gingival recession [6]. Periodontal conditions such as decreased keratinised gingival thickness and height, reduced alveolar bone thickness due to tooth malposition, presence

*Corresponding Author

Dr. Jaiganesh Ramamurthy,

Professor and Head of Department, Department of Periodontics, Saveetha Dental College and Hospitals, Saveetha Institute of Medical and Technical Sciences, Saveetha University,

Chennai, India.

Tel: 9840443463

E-mail: jaiganeshr@saveetha.com

Received: October 07, 2020

Accepted: November 22, 2020

Published: November 25, 2020

Citation: Janhvi Manohar, Jaiganesh Ramamurthy, S.P. Saravana Dinesh. Prevalence Of Gingival Recession In Patients Undergoing Orthodontic Treatment in the Age Group Of 18 To 25 Years - A Retrospective Study. Int J Dentistry Oral Sci. 2020;7(11):1084-1089. doi: http://dx.doi.org/10.19070/2377-8075-20000215

Copyright: Jaiganesh Ramamurthy ${ }^{\circ} 2020$. This is an open-access article distributed under the terms of the Creative Commons Attribution License, which permits unrestricted use, distribution and reproduction in any medium, provided the original author and source are credited. 
of dehiscence or fenestration, tapered tooth shaped are also common risk factors for gingival recession $[4,7,8]$.

Age related gingival recession is more prevalent in individuals older than 50 years without a gender predominance [9]. Other factors include calculus, use of a hard dental brush, high frenal attachment, position of the tooth in the arch, tooth movement by orthodontic forces such as excessive proclination of incisors, improper designed partial dentures, smoking, sub gingival restoration, chemicals like cocaine etc. $[10,11]$.

Orthodontic treatment is considered to be an iatrogenic factor that contributes to gingival recession [12-14]. Orthodontic tooth movement occurs by bone remodeling. Bone surrounding a tooth subjected to a force responds in the following manner: resorption occurs where there is pressure and new bone forms where there is tension. When pressure is applied to a tooth, there is an initial period of movement for six to eight days as the periodontal ligament (PDL) is compressed. Compression of the PDL results in blood supply being cut off to an area of the PDL and this produces an avascular cell-free zone by a process termed "hyalinization". When hyalinization occurs, the tooth stops moving. Once the hyalinized is removed, tooth movement can occur again [15]. Wennstrom et al., stated that as long as the tooth is moved within the envelope of the alveolar process, the risk of harmful side-effects on the marginal soft tissue is minimal. Thin, delicate tissue is far more prone to exhibit recession during orthodontic treatment when compared with normal, thick tissue [12]. There is considerable variation in both width and thickness of the gingiva, a fact that gives rise to the assumption that numerous gingival biotypes might exist in any adult population [16].

Although a well aligned dentition is favourable for maintaining periodontal health, recent systematic reviews support the association between orthodontic treatment and gingival recession [14].

Some studies have attributed movement of teeth with thin tissue biotype using a primate model, demonstrating that extensive bodily movement of teeth resulted in alveolar bone height reduction and apical displacement of gingiva [12]. This usually occurs with flaring of incisors to resolve crowding, expansion of dental arches to correct transverse discrepancies or retraction of anterior teeth to close extraction spaces. However, predisposing factors of gingival recession in orthodontic patients are not clear. The lack of appropriate occlusal stimulation disrupts the balance of the masticatory system and causes a series of changes such as root resorption and periodontal weakness. Treatment of gingival recession is usually done using grafts and attempting to regenerate lost tissue which is essentially a multifactorial process requiring a multi-dependent sequence of biological events, including celladhesion, migration, proliferation, and differentiation [17].

Previously, we have studied about TNF - alpha levels in types of periodontitis [18], isolating stem cells from oral cavity [19], effect of interleukin -[20,21], role of plasma rich in growth factors in treatment of intrabony defects [21], role of endothelin -1 in periodontal diseases [22, 23], COPD and periodontal disease [24], variations in course of inferior alveolar nerve [25], aesthetic lip repositioning [26], case reports on comprehensive rehabilitation using implants [27], association of bacteria in atheromatous and subgingival plaques [28], assessed knowledge of dental students on mouthwashes [29] and compared the effects of chlorhexidine and hiora mouthwashes in patients with gingivitis [30] however epidemiological studies are still lacking. Hence the aim of the present study was to analyse the prevalence of gingival recession in patients who were undergoing orthodontic treatment and analysing the biological plausibility between these two.

\section{Materials And Methods}

A retrospective study was carried out in a university setting among patients visiting a dental hospital, predominantly South Indian population. Patients who visited the department of Orthodontics; who were within the age group of 18 to 25 years, undergoing orthodontic treatment were chosen for the study. Patients' case records, pre operative intra operative photographs were checked for signs of gingival recession.

Records of the patients were obtained from Saveetha Dental College and Hospitals. The advantage of this methodology was the ease of access and the limitation was that the study was limited to a single metropolitan area. Approval for the study and permission to access patients records was obtained from the ethical review board of Saveetha Institute of Medical and Technical Sciences (SIMATS) with the approval number: SDC/SIHEC/2020/DIASDATA/0619-0320.

The case sheets of the patients visiting the Department of Orthodontics, undergoing orthodontic treatment were collected from the time period June 2019 to March 2020 within the age range of the sample being 18 to 25 years. 86,000 case records were checked and 347 patient records were chosen for the study who fulfilled the inclusion criteria. Patients with congenital syndromes causing facial deformities, smokers and those diagnosed psychological disorders were excluded from the study whereas patients within the age group of 18 to 25 years, undergoing orthodontic treatment were included in our study. Internal validity ensured by eliminating confounding factors and external validity was confirmed as the study was done with a South Indian population and the consensus can be applied to the general population. Cross verification was done by reviewing the recorded periodontal charts, preoperative and intra operative photographs and their plaque index scores.

Incomplete data was excluded from the study due to the possibility of bias. The data was collected, tabulated, frequency distribution charts were made on the number of patients presenting with gingival recession during or post orthodontic treatments. Descriptive statistics was performed using SPSS by IBM and Chi square tests were done.

\section{Results And Discussion}

Among a total of 347 patients chosen for this study, between the ages of 18 to 25 years, undergoing orthodontic treatment, $40.06 \%$ of the sample were clinically observed as having a Miller's class I gingival recession whereas only $0.6 \%$ were seen as having Millers Class II recession and the rest were observed as having no evidence of gingival recession while undergoing orthodontic treatment. Table 2 showed a non significant association $(\mathrm{p}>0.05)$ between plaque index or the presence of plaque and gingival recession among patients undergoing orthodontic treatment. According to graph 3 males were seen as more prone to gingival 
recession due to orthodontic treatment. Table 3 shows a positive but non significant correlation between gender of the patients and gingival recession due to orthodontic treatment.

Gingival recession, according to American Academy of Periodontology, is defined as, "Location of the gingival margin apical to the cemento-enamel junction" [31]. It may be caused by exogenous (mechanical trauma, bacterial toxins - periodontitis, post certain dental treatments, orthodontic treatment) or endogenous factors (traumatic bite) [32]. Periodontitis is one of the major etiological factors of gingival recession and is a host modulatory response initiated by bacterial toxins causing a chronic environment of inflammatory disease characterised by periodontal tissue damage. Periodontic-orthodontic interrelationship has been subject to a huge deal of investigation until today and continues being a controversial issue. Gingival recession following orthodontic treatment has been a debatable topic throughout the years. It is well known that forces due to orthodontic tooth movement or due to an abnormal bite can cause remodelling of periodontal tissue.
Orthodontic tooth movement is dependent on efficient remodelling of bone. The cell-cell interactions are now more fully understood and the links between osteoblasts and osteoclasts appear to be governed by the production and responses of osteoprotegerin ligands. The theories of orthodontic tooth movement remain speculative but the histological documentation is unequivocal. A periodontal ligament placed under pressure will result in bone resorption whereas a periodontal ligament under tension results in bone formation [33]. Frequent occlusal trauma increases the occlusal load and often leads to resorption of alveolar bone. When excessive, abnormal occlusal force is removed and normal bite force is restored through orthodontic treatment, alveolar bone is rebuilt with increased bone volume. However, in addition to the increased occlusal force abnormal occlusal force also comes under low occlusal function. Due to the loss of proper stimulation from occlusal forces the periodontal tissue recessively reacts through root resorption and alveolar bone resorption [34]. Studies done by Alstad et al reported that $10 \%$ of adolescents were

Table 1. Distribution of study population based on age and gender of patients in the sample.

\begin{tabular}{|c|c|c|c|}
\hline Age of the patients (Years) & Males & Females & Total \\
\hline 18 & $12(3.4 \%)$ & $18(5.1 \%)$ & $30(8.6 \%)$ \\
\hline 19 & $15(4.3 \%)$ & $16(4.6 \%)$ & $31(8.9 \%)$ \\
\hline 20 & $21(6.0 \%)$ & $12(3.4 \%)$ & $33(9.5 \%)$ \\
\hline 21 & $17(4.8 \%)$ & $30(8.6 \%)$ & $47(13.5 \%)$ \\
\hline 22 & $29(8.3 \%)$ & $24(6.9 \%)$ & $53(15.3 \%)$ \\
\hline 23 & $28(8.0 \%)$ & $31(8.9 \%)$ & $59(17.0 \%)$ \\
\hline 24 & $31(8.9 \%)$ & $17(4.8 \%)$ & $48(13.8 \%)$ \\
\hline 25 & $29(8.3 \%)$ & $17(4.8 \%)$ & $46(13.6 \%)$ \\
\hline TOTAL & $182(52.4 \%)$ & $165(47.6 \%)$ & $347(100.0 \%)$ \\
\hline
\end{tabular}

Graph 1. Bar graph representing frequency distribution of extent of gingival recession observed among patients (within the age group 18-25 years) undergoing orthodontic treatment. $X$ axis represents extent of gingival recession based on Miller's classification of gingival recession and $Y$ axis represents the total number of patients undergoing orthodontic treatment (Total number of cases in percentage). $40.1 \%$ of the population were observed as having Miller's class I type of gingival recession, $0.6 \%$, reported Miller's class II gingival recession.

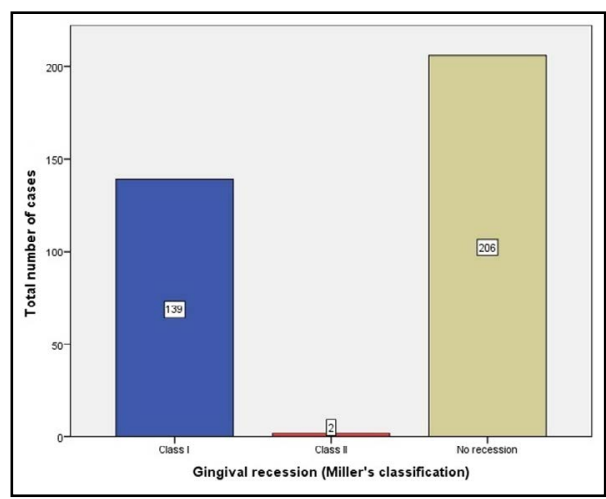

Table 2. Chi-square association test for extent of gingival recession and plaque index score of patients undergoing orthodontic treatment with the Pearson Chi-square: 7.965 and p value: 0.668 . This suggests a positive correlation but a non significant association between gingival recession and plaque accumulation in patients undergoing orthodontic treatment.

\begin{tabular}{|c|c|c|c|}
\hline & Value & df & Asymp. Sig(2-sided) \\
\hline Pearson Chi-square & $7.965^{\mathrm{a}}$ & 4 & 0.093 \\
\hline Likelihood Ratio & 9.663 & 4 & 0.047 \\
\hline Linear-by-Linear Association & 0.64 & 1 & 0.422 \\
\hline No of Valid Cases & 345 & & \\
\hline
\end{tabular}


Graph 2. Bar graph representing association between extent of gingival recession (Miller's classification) and plaque index score. $\mathrm{X}$ axis represents the total number of patients undergoing orthodontic treatment and $\mathrm{Y}$ axis represents extent of gingival recession based on Miller's classification of gingival recession. Plaque index scores were in the minimal range in all the three groups than the other scores. However, the difference is not significant statistically. Pearson chi square value: 7.965 , $\mathrm{p}$ value: $0.093(\mathrm{p}>0.05)$.

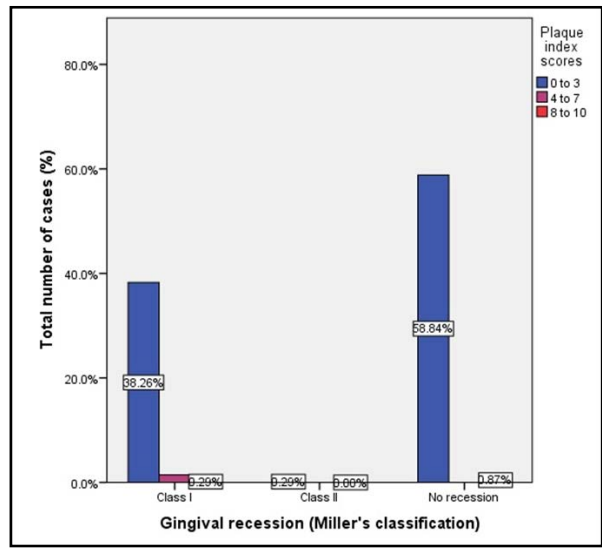

Table 3. Chi-square association test for extent of gingival recession and gender of patients undergoing orthodontic treatment with the Pearson Chi-square: 0.807 and p value: 0.668 . This suggests a positive correlation but a non significant association between gingival recession and gender of patients undergoing orthodontic treatment.

\begin{tabular}{|c|c|c|c|}
\hline & Value & df & Asymp. Sig(2-sided) \\
\hline Pearson Chi-square & $0.807^{\mathrm{a}}$ & 2 & 0.668 \\
\hline Likelihood Ratio & 0.808 & 2 & 0.668 \\
\hline Linear-by-Linear Association & 0.798 & 1 & 0.372 \\
\hline No of Valid Cases & 347 & & \\
\hline
\end{tabular}

Graph 3. Bar graph representing association between extent of gingival recession (Miller's classification) and gender of patients undergoing orthodontic treatment. $\mathrm{X}$ axis represents the total number of patients undergoing orthodontic treatment and $\mathrm{Y}$ axis represents extent of gingival recession based on Miller's classification of gingival recession. There is no difference of gingival recession during orthodontic treatment between males and females and the difference is also not statistically significant. Pearson chi square value: $0.807, \mathrm{p}$ value: $0.66(\mathrm{p}>0.05)$.

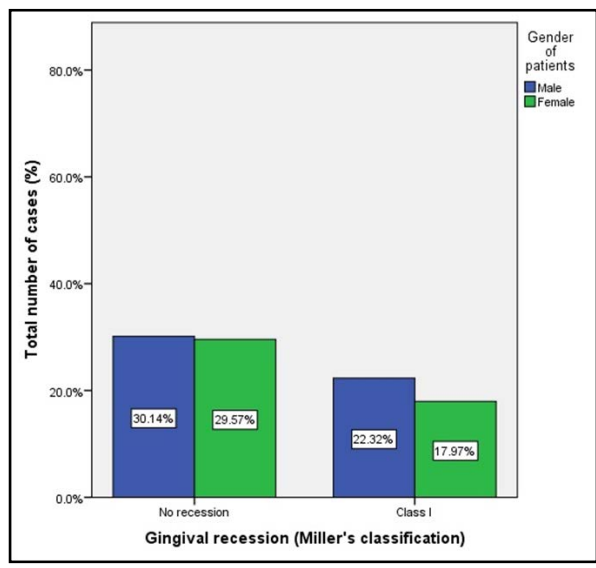

observed as having significant loss of attachment (mean 1-2 mm) in two years and stated orthodontic treatment has minimal detrimental effects on the health of the periodontium in both the short- and long-term [35].

Our study reports that $40.06 \%$ of the patients within the age group of 18 to 25 years were clinically observed as having gingival recession either post or during orthodontic treatment. This data coincides with the reports stated by Juan Ji et al., [34] who compared the extent of recession before and after orthodontic treatment, there was a 30 to $40 \%$ increase in the incidence of gingival recession. This report is sufficient to say that orthodontic tooth movement is one of the important etiological agents of gingival recession and if superimposed with inadequate oral hygiene, it can cause deleterious effects thus hampering the entire idea of the orthodontic treatment. In most cases, orthodontic treatments are opted by patients to gain a more aesthetic appearance and a pleasing smile, gingival recession caused by orthodontic tooth movement changes the appearance of the final outcome of the treatment as explained to the patient. This reason is enough to identify the specifics of orthodontic tooth movement such as the type of appliances used or brackets or the material of the wires and if they aggravate the forces on the periodontal ligament and bone.

A non significant association between plaque index and the extent of gingival recession has been noted. This chi square test was performed to check if plaque accumulation had a significant role to play in causing or further worsening gingival recession. It can be conferred from this data that the forces of orthodontic tooth movement is sufficient to cause gingival recession even in the absence of plaque accumulation. It can also be conferred that irrespective of having high plaque scores, gingival recession was not 
noted. Previous animal studies have stated that in the absence of plaque accumulation, orthodontic forces and tooth movements alone does not cause gingivitis or recession [36-38]. Study done by Juan J et al., reported a similar finding where there was no effect of plaque accumulation (calculated in the form of plaque index) on the gingival recession caused [34].

However, periodontitis is a host modulated response and may vary among humans and animals, further in-vivo studies on the same are required to draw conclusions.

While assessing the gender distribution of the extent of gingival recession, males were found to be more commonly observed with gingival recession due to orthodontic tooth movement than females. This can be explained by increased awareness and maintenance of oral hygiene by females as they are more concerned about their appearance. A contradicting statement by Juan Ji et al., reported that $61.1 \%$ of females and $51.7 \%$ males were observed with gingival recession post orthodontic treatment [34]. However, the difference between males and females is small and not significant enough to be taken into account.

Further understanding the mechanism and precise appreciation of the treatment and associated complications will aid us in coming up with newer treatment modalities having less complications and better patient satisfaction.

\section{Conclusion}

From the study done it can be concluded that within the limits of the study, $40.6 \%$ of the patients undergoing orthodontic treatment were observed to experience minimal gingival recession generally Miller's Class I type and the gingival recession caused has no association and is independent of plaque accumulation. Further studies on the same are necessary to understand gingival recession due to orthodontic treatment, contributing local and general factors to educate dental practitioners which will aid in effective treatment and expected outcomes.

\section{Acknowledgments}

I would like to thank the Chancellor, Director of academics and the Dean of Saveetha Dental College for the constant encouragement with my work during all stages of the study.

\section{References}

[1]. Manohar J. Anti-protease activity of Lavender on Chronic Periodontitis patients-An Ex-vivo study. Asian J. Pharm. Res. 2020;10(2):95-100.

[2]. Thamaraiselvan M, Elavarasu S, Thangakumaran S, Gadagi JS, Arthie T. Comparative clinical evaluation of coronally advanced flap with or without platelet rich fibrin membrane in the treatment of isolated gingival recession. J Indian Soc Periodontol. 2015 Jan;19(1):66-71.

[3]. Ramesh A, Varghese SS, Doraiswamy JN, Malaiappan S. Herbs as an antioxidant arsenal for periodontal diseases. J Intercult Ethnopharmacol. 2016 Jan 27;5(1):92-6.Pubmed PMID: 27069730.

[4]. Kassab MM, Cohen RE. The etiology and prevalence of gingival recession. J Am Dent Assoc. 2003 Feb 1;134(2):220-5.

[5]. Dilsiz A, Aydin T. Gingival recession associated with orthodontic treatment and root coverage. 2010.

[6]. Abboud M, Grüner M, Koeck B. Anterior crowding-just an esthetic problem?. J Orofac Orthop. 2002 Apr 1;63(4):264-73.

[7]. Joss-Vassalli I, Grebenstein C, Topouzelis N, Sculean A, Katsaros C. Orthodontic therapy and gingival recession: a systematic review. Orthod Craniofac
Res. 2010 Aug;13(3):127-41.

[8]. Vanarsdall RL, Secchi AG. Periodontal/orthodontic interrelationships. Orthodontics: current principles and techniques. St Louis/Missouri. 1994.

[9]. Allais D, Melsen B. Does labial movement of lower incisors influence the level of the gingival margin? A case-control study of adult orthodontic patients. Eur J Orthod. 2003 Aug;25(4):343-52.Pubmed PMID: 12938839.

[10]. Gunsolley JC, Quinn SM, Tew J, Gooss CM, Brooks CN, Schenkein HA. The effect of smoking on individuals with minimal periodontal destruction. J Periodontol. 1998 Feb;69(2):165-70.Pubmed PMID: 9526915.

[11]. Parma-Benfenati S, Fugazzato PA, Ruben MP. The effect of restorative margins on post-surgical development and nature of periodontium. 1985;

[12]. Wennström JL, Lindhe J, Sinclair F, Thilander B. Some periodontal tissue reactions to orthodontic tooth movement in monkeys. J Clin Periodontol. 1987 Mar;14(3):121-9.

[13]. Bollen AM, Cunha-Cruz J, Bakko DW, Huang GJ, Hujoel PP. The effects of orthodontic therapy on periodontal health: a systematic review of controlled evidence. J Am Dent Assoc. 2008 Apr 1;139(4):413-22.

[14]. Slutzkey S, Levin L. Gingival recession in young adults: occurrence, severity, and relationship to past orthodontic treatment and oral piercing. Am J Orthod Dentofacial Orthop. 2008 Nov;134(5):652-6.Pubmed PMID: 18984397.

[15]. Proffit WR, Fields Jr HW, Sarver DM. Contemporary orthodontics. Elsevier Health Sciences; 2006 Dec 8:768.

[16]. S. Sripradha, Jaiganesh Ramamurthy, Thummala Bhagyalakshmi. To compare the effectiveness of chlorhexidine Extended Protection on patients with and without gingivitis - A clinical trial. Drug Invention Today. 2018 Dec;10(4):3670-5.

[17]. Panda S, Jayakumar ND, Sankari M, Varghese SS, Kumar DS. Platelet rich fibrin and xenograft in treatment of intrabony defect. Contemp Clin Dent. 2014 Oct;5(4):550-4.Pubmed PMID: 25395778.

[18]. Varghese SS, Thomas H, Jayakumar ND, Sankari M, Lakshmanan R. Estimation of salivary tumor necrosis factor-alpha in chronic and aggressive periodontitis patients. Contemp Clin Dent. 2015 Sep;6(Suppl 1):S152-6. Pubmed PMID: 26604566.

[19]. Avinash K, Malaippan S, Dooraiswamy JN. Methods of Isolation and Characterization of Stem Cells from Different Regions of Oral Cavity Using Markers: A Systematic Review. Int J Stem Cells. 2017 May 30;10(1):12-20. Pubmed PMID: 28531913.

[20]. Mootha A, Malaiappan S, Jayakumar ND, Varghese SS, Toby Thomas J. The Effect of Periodontitis on Expression of Interleukin-21: A Systematic Review. Int J Inflam. 2016;2016:3507503.Pubmed PMID: 26998377.

[21]. Ravi S, Malaiappan S, Varghese S, Jayakumar ND, Prakasam G. Additive Effect of Plasma Rich in Growth Factors With Guided Tissue Regeneration in Treatment of Intrabony Defects in Patients With Chronic Periodontitis: A Split-Mouth Randomized Controlled Clinical Trial. J Periodontol. 2017 Sep;88(9):839-845.Pubmed PMID: 28474968.

[22]. Khalid W, Varghese SS, Sankari M, Jayakumar ND. Comparison of Serum Levels of Endothelin-1 in Chronic Periodontitis Patients Before and After Treatment. J Clin Diagn Res. 2017 Apr;11(4):ZC78-ZC81.Pubmed PMID: 28571268.

[23]. Khalid W, Vargheese SS, Lakshmanan R, Sankari M, Jayakumar ND. Role of endothelin-1 in periodontal diseases: A structured review. Indian J Dent Res. 2016 May-Jun;27(3):323-33.Pubmed PMID: 27411664.

[24]. Ramesh A, Varghese SS, Jayakumar ND, Malaiappan S. Chronic obstructive pulmonary disease and periodontitis-unwinding their linking mechanisms. J Oral Biosci. 2016 Feb 1;58(1):23-6.

[25]. Kavarthapu A, Thamaraiselvan M. Assessing the variation in course and position of inferior alveolar nerve among south Indian population: A cone beam computed tomographic study. Indian J Dent Res. 2018 JulAug;29(4):405-409.Pubmed PMID: 30127186.

[26]. Ramesh A, Vellayappan R, Ravi S, Gurumoorthy K. Esthetic lip repositioning: A cosmetic approach for correction of gummy smile - A case series. J Indian Soc Periodontol. 2019 May-Jun;23(3):290-294.Pubmed PMID: 31143013.

[27]. Ramesh A, Ravi S, Kaarthikeyan G. Comprehensive rehabilitation using dental implants in generalized aggressive periodontitis. J Indian Soc Periodontol. 2017 Mar-Apr;21(2):160-163.Pubmed PMID: 29398863.

[28]. Priyanka S, Kaarthikeyan G, Nadathur JD, Mohanraj A, Kavarthapu A. Detection of cytomegalovirus, Epstein-Barr virus, and Torque Teno virus in subgingival and atheromatous plaques of cardiac patients with chronic periodontitis. J Indian Soc Periodontol. 2017 Nov-Dec;21(6):456-460.Pubmed PMID: 29551863

[29]. Niveda R, Jaiganesh R. Knowledge and attitude toward mouthwashes and their uses among dental undergraduate and postgraduate students. Drug Invent. Today. 2019 Jun 1;12(6).

[30]. RAMAMURTHY J. COMPARISON OF EFFECT OF HIORA MOUTHWASH VERSUS CHLORHEXIDINE MOUTHWASH IN GINGIVITIS 
PATIENTS: A CLINICAL TRIAL. Asian J Pharm Clin Res. 2018;11(7):848.

[31]. Cohen RE, Mariotti A, Rethman M, Zackin SJ. Glossary of periodontal terms. Chicago: The American Academy of Periodontology. 2001;

[32]. Baker P, Spedding C. The aetiology of gingival recession. Dent Update. 2002 Mar 2;29(2):59-62.

[33]. Roberts-Harry D, Sandy J. Orthodontics. Part 11: orthodontic tooth movement. Br Dent J. 2004 Apr 10;196(7):391-4; quiz 426.Pubmed PMID: 15071525.

[34]. Ji JJ, Li XD, Fan Q, Liu XJ, Yao S, Zhou Z, et al. Prevalence of gingival recession after orthodontic treatment of infraversion and open bite. J Orofac Orthop. 2019 Jan;80(1):1-8.Pubmed PMID: 30242441.

[35]. Alstad S, Zachrisson BU. Longitudinal study of periodontal condition as- sociated with orthodontic treatment in adolescents. Am J Orthod. 1979 Sep;76(3):277-86.Pubmed PMID: 290273.

[36]. Ericsson I, Thilander B. Orthodontic forces and recurrence of periodontal disease. An experimental study in the dog. Am J Orthod. 1978 Jul;74(1):4150.

[37]. Ericsson I, Thilander B. Orthodontic relapse in dentitions with reduced periodontal support: an experimental study in dogs. Eur. J. Orthod. 1980 Jan 1;2(1):51-7.

[38]. Ericsson I, Thilander B, Lindhe J. Periodontal conditions after orthodontic tooth movements in the dog. Angle Orthod. 1978 Jul;48(3):210-8.Pubmed PMID: 280130. 